\title{
Razor Clam (Ensis directus) Shell as a Low-Cost Adsorbent for Anionic and Cationic Dyes in Aqueous Solutions
}

\author{
Lila Elamari Mohamed Areibat, Azlan Kamari, and Shahrulnizahana Mohammad Din
}

\begin{abstract}
The ultimate objective of this study was to investigate the potential application of razor clam (Ensis directus) shell (RCS) for the removal of synthetic dyes from aqueous solutions. Adsorption of anionic dye (congo red, CR) and cationic dye (methylene blue, MB) was studied under different experimental conditions such as initial $\mathrm{pH}$ solution, adsorbent dosage and initial dyes concentration. High affinity of CR towards RCS was obtained at an acidic medium (pH 2.0), while alkaline medium ( $\mathrm{pH} \mathrm{8.0)}$ was favourable for $\mathrm{MB}$ adsorption. The removal for both dyes exhibited a reverse trend with increasing the initial dyes concentration. Adsorption equilibrium data were fitted to Freundlich and Langmuir isotherm models. A better correlation $\left(R^{2}>0.95\right)$ was obtained with Freundlich isotherm model. The adsorption capacity $\left(K_{\mathrm{F}}\right)$ of RCS for CR and MB was estimated as 6.52 and $0.66 \mathrm{mg} / \mathrm{g}$, respectively. The regeneration of RCS was evaluated in a desorption study, of which hydrochloric acid $(\mathrm{HCl})$ and acetic acid $\left(\mathrm{CH}_{3} \mathrm{COOH}\right)$ was used as desorption agents. $\mathrm{HCl}(0.5$ $\mathrm{mol} / \mathrm{L}$ ) was the best desorption agent, due to its ability to desorb $81 \%$ of CR and $67 \%$ of MB. The feasibility of RCS was compared with olive tree derived activated carbon, a commercial adsorbent for water treatment in Libya. Based on results obtained from competitive and comparative studies, it can be concluded that RCS, a fishery waste-based material, is a promising low-cost adsorbent for the remediation of water contaminated with toxic dyes.
\end{abstract}

Index Terms-Synthetic dyes, razor clam shell, adsorbent, isotherm models, wastewater.

\section{INTRODUCTION}

Synthetic dyes are extensively used to impart colour to the substrates in various branches of textile industries, pulp and paper industries, leather tanning industries, food industries and etc. [1]. The textile industry by far used the most amounts of synthetic dyes for colouring fibres. It was estimated that about 88.5 million tonnes of textiles production use various types of synthetic dyes annually [2]. Dyes are present in industrial wastewater because some of them do not bind to the substrate (fibre) during the dyeing process. The loss of dyes in effluents can vary from $2 \%$ to $50 \%$, subject to the class of dye used. The loss of reactive dyes is higher than any other classes. The high degree of loss of reactive dyes could be the result of the hydrolysed form of reactive dyes, which

Manuscript received September 20, 2018; revised November 12, 2018.

Lila Elamari Mohamed Areibat and Azlan Kamari are with the Department of Chemistry, Faculty of Science and Mathematics, Universiti Pendidikan Sultan Idris, 35900, Tanjong Malim, Perak, Malaysia (e-mail: azlan.kamari@fsmt.upsi.edu.my).

Shahrulnizahana Mohammad Din is with the Department of Chemistry, Johore State, Jalan Abdul Samad, 80100, Johor Bahru, Johor, Malaysia. have no ability to bind with fibres [3].

The colour effluents discharge into water bodies is of great public concern mainly due to the potential threat to human health, especially the entry of noxious constituents into the food chains of organisms [4]. Their intake, although at trace amounts, could lead to health problems to mankind as well as animals [5]. CR and MB are widely used in textile, silk, hair colourant, paper, wood, wools and other industries [1], [6]. CR may cause allergic reaction, blood clotting, induce somnolence and respiratory problems. Meanwhile, MB may cause dyspnea, increase heart rate, nausea, eye burn and irritation to the skin [1], [7].

Dye effluent can be characterised based on its complex organic content, high salt content, and stability to withstand degradation by light, chemical, biological and other factors. This makes them difficult to degrade [5], [8]. Therefore, it is necessary to reduce the negative impact of this effluent on human health and the environment, which can be achieved by finding a suitable technology to treat wastewater before its discharge. Hitherto, numerous of physical, chemical and biological methods to sequester toxic dyes from aqueous solutions have been investigated. The best technique for treatment depends on type of dyes to be removed, their composition and concentrations [8].

Adsorption has been recognised as one of the most promising and successful strategies to remove dyes from industrial effluents [6]. It has been considered as an economical process, highly efficient, simple system which does not require additional reagents. Moreover, it requires minimal use of chemicals and does not generate toxic sludge [6], [9]. The agricultural by-products have received great attention from environmental scientists to use them as adsorbents, which due to their high carbonaceous contents (lignin, cellulose, and hemicelluloses), functional groups, and their physicochemical characteristics [10]. Bengal gram seed husk [11], mango leaf [12], spruce sawdust [13], durian seed [14] and sugarcane bagasse [15] have been employed as clean-up materials for treating industrial wastewater. Using untreated agricultural wastes could result in low adsorption capacity and discharge of soluble organic compounds contained in the plant materials [16].

One of the alternative materials for removing dyes from aqueous solution is razor clam (Ensis directus) shell, which has unique features that enable it to be used as an adsorbent. It has low economic value since it is a fishery waste, abundant in the nature, no odour or hazardous waste is produced during the treatment process. Furthermore, it is primarily composed of calcium carbonate, which can be beneficial for adsorption mechanism [17]. The overall goal of 
this study was to assess the potential of RCS as an adsorbent for the removal of $\mathrm{CR}$ and $\mathrm{MB}$ from aqueous solutions. The effectiveness of RCS was affected by three experimental factors, namely solution $\mathrm{pH}$, adsorbent dosage and initial dye concentration. The equilibrium adsorption data were described by Freundlich and Langmuir isotherm models. SEM and FTIR analyses were carried out to elucidate the adsorption behaviour. The applicability of RCS was further evaluated in terms of desorption, comparative and competitive studies.

\section{PROCEDURE}

\section{A. Preparation of Adsorbent}

Razor clam shells were collected from a seafood restaurant in Tanjong Malim, Perak. The shells were washed several times with tap water and rinsed by deionised water to remove dust and unwanted particles. The oven dry method was used for drying the shells at temperature $70{ }^{\circ} \mathrm{C}$ for 24 hours. The dried materials were crushed using a laboratory mill and then sieved through an American Society for Testing Materials (ASTM) standard sieve to obtain a particle size of 150-250 $\mu \mathrm{m}$. The RCS powder was then stored in airtight container for protection from moisture.

\section{B. Preparation of Adsorbate}

All chemicals used in this study were of analytical grade and used as received. To prepare $100 \mathrm{mg} / \mathrm{L}$ dye stock solution, specific amount (100 mg) of CR (Bendosen Laboratory Chemistry) and MB (Merck KGaA) were dissolved individually in deionised water. Dye solutions of required concentrations were prepared from the stock solution through serial dilution. All dye solutions were prepared in volumetric flasks and were stored in the dark to prevent light degradation. The chemical structure of CR and MB dyes are given in Fig. 1.

(a)

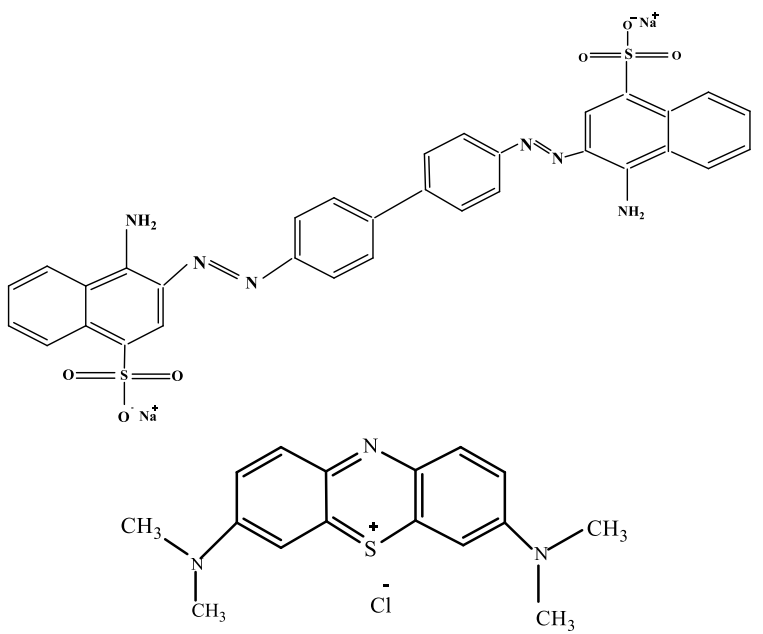

(b)

Fig. 1. Chemical structure of CR (a) and MB (b).

\section{Characterisation Study}

Several physicochemical properties of RCS were characterised in this study using:

1) Micromeritics surface analyser
Textural characterisation of RCS in terms of specific surface area and the average pore diameter were determined by nitrogen adsorption-desorption isotherms using a Quantachrom Autosorb I Micromeritics Surface Analyser. The surface area was computed according to Brunauer-Emmett-Teller (BET) method [18], while the Barrett-Joyner-Halenda (BJH) model was applied for determining the pore volume and pore diameter [19].

2) Scanning electron microscope (SEM)

The surface morphology of RCS before and after dye uptake was characterised by using a Hitachi SU 8020 UHR Field Emission Scanning Electron Microscope. To avoid electron charging effect, RCS was coated with a thin layer of platinum prior to analysis. The SEM analysis was conducted at an electron acceleration voltage of $5.0 \mathrm{kV}$ to obtain a suitable image resolution.

\section{3) Fourier transform infrared (FTIR) spectrometer}

The FTIR spectra of RCS before and after adsorption performance were obtained by using a Thermo Nicolet 6700 FTIR Spectrometer. The spectra were recorded in the range of wavenumbers between 4000 and $400 \mathrm{~cm}^{-1}$ with 32 cumulative scans at $4 \mathrm{~cm}^{-1}$ resolution. The functional group of RCS and possible binding mechanism(s) between the active sites of RCS and dye molecules were studied by FTIR analysis.

\section{Adsorption Study}

The adsorption experiments were performed by shaking $0.5 \mathrm{~g}$ of RCS powder in a conical flask contained $50 \mathrm{~mL}$ of 5 $\mathrm{mg} / \mathrm{L}$ of dye solution using a Protech Orbital Shaker (model 720), with operating speed of $100 \mathrm{rpm}$ for 1 hour. Following agitation, the solutions were filtered through a filter paper (Filter Fioroni 601). Finally, the residual concentrations of the unadsorbed dyes in the supernatant were measured using UV-Visible Spectrophotometry technique. The equilibrium concentrations of dye were analysed at the maximum wavelength $\left(\lambda_{\max }\right)$. The maximum wavelength for CR was $499 \mathrm{~nm}$, while for MB was $665 \mathrm{~nm}$. The SEM and FTIR techniques were used to characterise the dried filtrates (RCS after adsorption).

The influence of several experimental parameters on dye adsorption by RCS was evaluated. Firstly, the effect of initial solution $\mathrm{pH}$ was studied in the range of $\mathrm{pH} 2.0-8.0$. The initial $\mathrm{pH}$ value was adjusted using either $0.1 \mathrm{~mol} / \mathrm{L} \mathrm{HCl}$ or $0.1 \mathrm{~mol} / \mathrm{L} \mathrm{NaOH}$. The measurement of $\mathrm{pH}$ was done by using a Thermo Scientific Orion 2-Star pH meter. Meanwhile, the effect of adsorbent dosage was studied using four dosages of RCS, namely $0.025,0.050,0.100$ and $0.200 \mathrm{~g}$. Finally, the effect of initial dye concentration was carried out within concentration range of $2.5-100 \mathrm{mg} / \mathrm{L}$. The adsorption capacity of RCS at equilibrium was estimated by using equation (1):

$$
q_{\mathrm{e}}=\left(\frac{C_{\mathrm{o}}-C_{\mathrm{e}}}{W}\right) V
$$

where $q_{\mathrm{e}}$ is the amount of dye adsorbed by RCS $(\mathrm{mg} / \mathrm{g}) . C_{\mathrm{o}}$ and $C_{\mathrm{e}}$ are the initial and equilibrium concentrations of dye solution $(\mathrm{mg} / \mathrm{L})$, respectively. $W$ is the weight of RCS $(\mathrm{g})$, and $V$ is the volume of dye solution $(\mathrm{L})$. 
The percentage of dye removed from the aqueous solutions was computed using equation (2):

$$
\left(\frac{C_{\mathrm{o}}-C_{\mathrm{e}}}{C_{\mathrm{o}}}\right) \times 100
$$

\section{E. Desorption Study}

The desorption experiments in the present study used $\mathrm{HCl}$ and $\mathrm{CH}_{3} \mathrm{COOH}$ as desorption agents. The adsorption process was conducted using $5 \mathrm{mg} / \mathrm{L}$ of dye, optimum $\mathrm{pH}$ and $0.500 \mathrm{~g}$ of RCS. After completing the adsorption experiment, the dye loaded onto RCS was eluted with $50 \mathrm{~mL}$ of varying concentrations $\left(5 \times 10^{-2}, 1 \times 10^{-1}, 5 \times 10^{-1} \mathrm{M}\right)$ of $\mathrm{HCl}$ and $\mathrm{CH}_{3} \mathrm{COOH}$. The mixture was stirred at an agitation rate of $100 \mathrm{rpm}$ for 1 hour. After filtration, the amount of desorbed dye was analysed by using an Agilent Cary 60 UV-Visible Spectrophometer. The percentage of desorption was calculated using equation (3):

$$
\text { Desorption }(\%)=\frac{M_{r}}{M_{0}} ? 100
$$

where $M_{\mathrm{r}}$ and $M_{0}$ are the weights of desorbed and adsorbed dyes (mg), respectively.

\section{F. Competitive and Comparative Adsorption Studies}

The competitive and comparative studies were taken under the following conditions: $0.500 \mathrm{~g}$ of the adsorbents and the initial dye concentration of 20 and $100 \mathrm{mg} / \mathrm{L}$. The commercial activated carbon (CAC) used in the comparative adsorption study is derived from the stem of olive tree and is produced in Libya. This part of experiment was run without pH adjustment.

\section{RESULT AND DiSCUSSION}

\section{A. Characterisation Study}

\section{1) Surface area and pore characteristics}

The BET surface area, pore diameter and the total pore volume of RCS were determined as $2.74 \mathrm{~m}^{2} / \mathrm{g}, 1.83 \AA$ and $0.2235 \mathrm{~cm}^{3} / \mathrm{g}$, respectively. According to the classification that adopted by the International Union of Pure and Applied Chemistry (IUPAC) for the pore diameter, the RCS adsorbent exhibited the microporous structure $(\mathrm{d}<20 \AA)$ [20]. It is interesting to highlight that the BET surface area of RCS is slightly higher than several adsorbent materials. For example, the BET surface area of raw pine cone and acid-treated pine cone was reported as $0.099 \mathrm{~m}^{2} / \mathrm{g}$ and 0.122 $\mathrm{m}^{2} / \mathrm{g}[21]$, respectively.

\section{2) SEM analysis}

Fig. 2 presents the surface morphology of RCS before and after dyes uptake. As depicted in Fig. 2(a), RCS appears to have a flat, dense and smooth surface texture. In contrast, the surface of RCS was entirely covered with solid particles following interaction with CR and MB (Figs. 2(b) and 2(c)). Additionally, the surface texture of RCS became rougher after the interaction. Results from SEM analysis indicate the applicability of RCS for CR and MB adsorption.

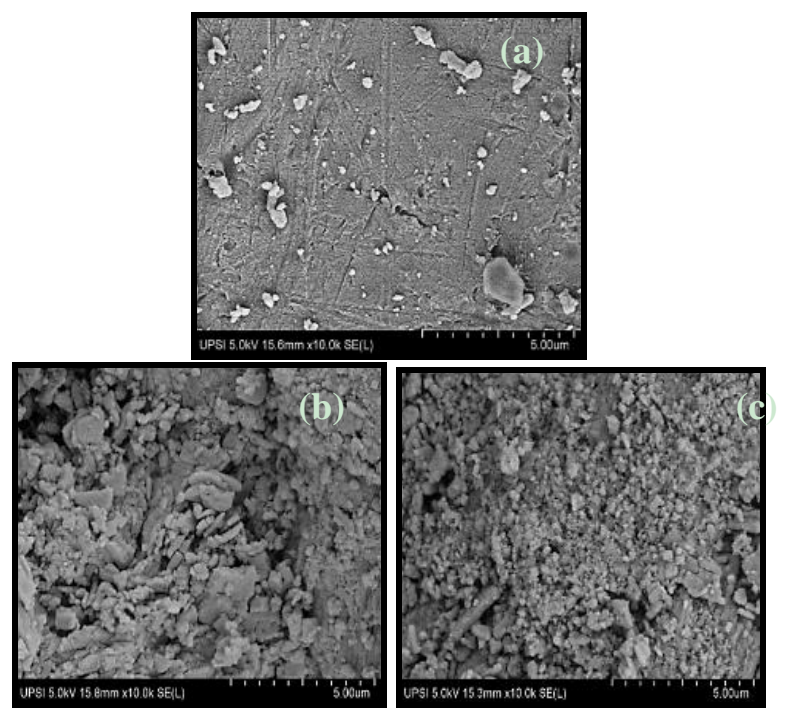

Fig. 2. SEM images of RCS before (a) and after interaction with CR (b) and MB (c) at 10,000x magnification.

\section{3) FTIR analysis}

The FTIR spectrum of RCS is presented in Fig. 3(a). It is apparent that several discernible absorption bands were appeared between wavenumber 1500 and $400 \mathrm{~cm}^{-1}$. Based on Fig. 3(a), the prominent absorption peaks at 1786, 1463, 855 and $712 \mathrm{~cm}^{-1}$ represent the characteristics of the carbonate $\left(\mathrm{CO}_{3}{ }^{2-}\right)$ group. Similar vibrational bands were observed by Bazbaş \& Boz [22] when they conducted the FTIR analysis for Anadara inaequivalvis (cockle) shells. As shown in Figs. 3(b) and 3(c), the FTIR spectra of RCS after dyes uptake revealed a similarity in the change of wavenumbers. This suggests a similar mechanism might involve for dyes uptake by RCS. For example, the absorption bands shifted from $1463 \mathrm{~cm}^{-1}$ to 1456 and $1453 \mathrm{~cm}^{-1}$. In addition, the peak at wavenumber $1786 \mathrm{~cm}^{-1}$ was found to shift to 1787 and 1785 $\mathrm{cm}^{-1}$ following $\mathrm{CR}$ and $\mathrm{MB}$ adsorption. RCS loaded CR and MB has caused the shift in wavenumber from $855 \mathrm{~cm}^{-1}$ to 854 $\mathrm{cm}^{-1}$. At the same time, some of peak intensities became lower after adsorption of dyes.

Presumably, the shift in wavenumbers of functional groups and the change in the absorption intensities could be ascribed to the involvement of functional groups available on the surface of RCS in the adsorption process. Overall, it can be concluded that carbonate groups might be the main adsorption sites that responsible for binding dyes to RCS surface. Kamari, Putra, Abd Wahid and Yusoff [23] also claimed that carbonate groups are accountable in the adsorption process.

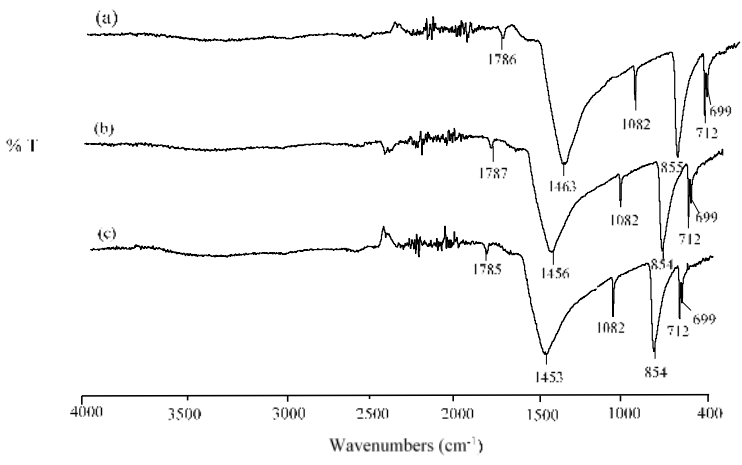

Fig. 3. FTIR spectra of RCS (a), RCS-CR (b) and RCS-MB. 


\section{B. Adsorption Study}

\section{1) Effect of initial pH of the solution}

Adsorption of dye is entirely $\mathrm{pH}$ dependent. This scenario can be ascribed to its influence on surface charge by protonation and deprotonation of the adsorbent materials and the nature of the dye structure as well [24]. The highest affinity of CR towards the adsorbent was observed at very acidic medium of which the maximum adsorption removal of $100 \%$ occurred at $\mathrm{pH} 2.0$ (Fig. 4). At this $\mathrm{pH}$, there is an overpopulation of $\mathrm{H}^{+}$ions and the surface of adsorbent gain a positive charge by absorbing the $\mathrm{H}^{+}$ions [11]. Consequently, the protonation of active sites favoured the adsorption of anionic dye due to a higher electrostatic interaction between protonated functional groups in the adsorbent and the sulphonate (SO3-) groups in the anionic dyes [6]. On other hand, the increase in the $\mathrm{pH}$ of the solution produces considerable electrostatic repulsion between the negatively charged carbonate groups and the deprotonated groups of anionic dyes due to the presence of the hydroxyl groups (OH-) [25]. This results in retardation of diffusion and diminished adsorption removal of $\mathrm{CR}$ to $74.06 \%$ at $\mathrm{pH}$ 8.0. Thereby, $\mathrm{pH}$ 2.0 was chosen as the optimum $\mathrm{pH}$ for the subsequent stages, which is supported with other previous works [26].

In regards $\mathrm{MB}$, the adsorption removal was observed to ascend from $25.99 \%$ to $88.70 \%$ as $\mathrm{pH}$ increases (Fig. 4). Under alkaline condition ( $\mathrm{pH} 8.0$ ), MB dye carries a positive charge $\left(-S^{+}\right)$that is strongly attracted to the negative adsorption sites of the adsorbent due to the deprotonation of the adsorbent [27]. As the available active sites are deprotonated, the electrostatic attraction increases and the uptake of MB dye is maximised [28]. On the contrary, the competition between excess $\mathrm{H}^{+}$ions and cationic $\mathrm{MB}$ dye molecule for binding sites in acidic medium results in reduced dye adsorption [29]. The optimal $\mathrm{pH}$ for $\mathrm{MB}$ dye adsorption by RCS was 8.0. This finding is similar to that made by other researchers [30].

\section{2) Effect of adsorbent dosage}

The dose of adsorbent is another parameter which has a strong influence on dye adsorption. From environmental engineering viewpoint, this experimental parameter is crucial, especially in determining the cost of treatment when using a particular adsorbent per unit of dye solution [31].

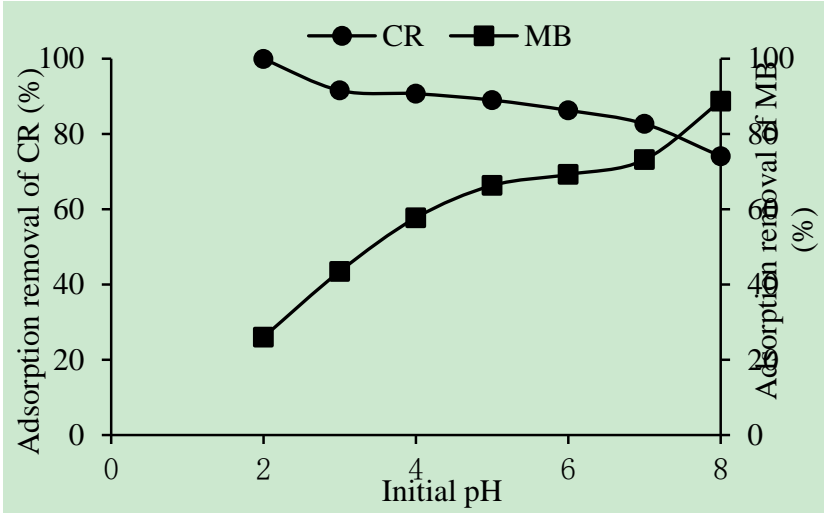

Fig. 4. Effect of initial solution $\mathrm{pH}$ on adsorption removal of dyes onto RCS; $C_{\mathrm{i}}=5 \mathrm{mg} / \mathrm{L}, W=0.5 \mathrm{~g}, T=25^{\circ} \mathrm{C}$.

Fig. 5 shows the effect of dose of adsorbent on dye adsorption. An increase in the adsorbent dosage from $0.025 \mathrm{~g}$ to $0.200 \mathrm{~g}$ has reduced adsorption capacity of both dyes. For example, the adsorption capacity of $\mathrm{CR}$ and MB decrease from 9.55 and $8.42 \mathrm{mg} / \mathrm{g}$ to 1.25 and $1.08 \mathrm{mg} / \mathrm{g}$, respectively. This phenomenon could be related to the aggregation and agglomeration of adsorbent particles, particularly at higher adsorbent concentrations which reduces the intercellular distance and block some of the active sites for adsorption [20].
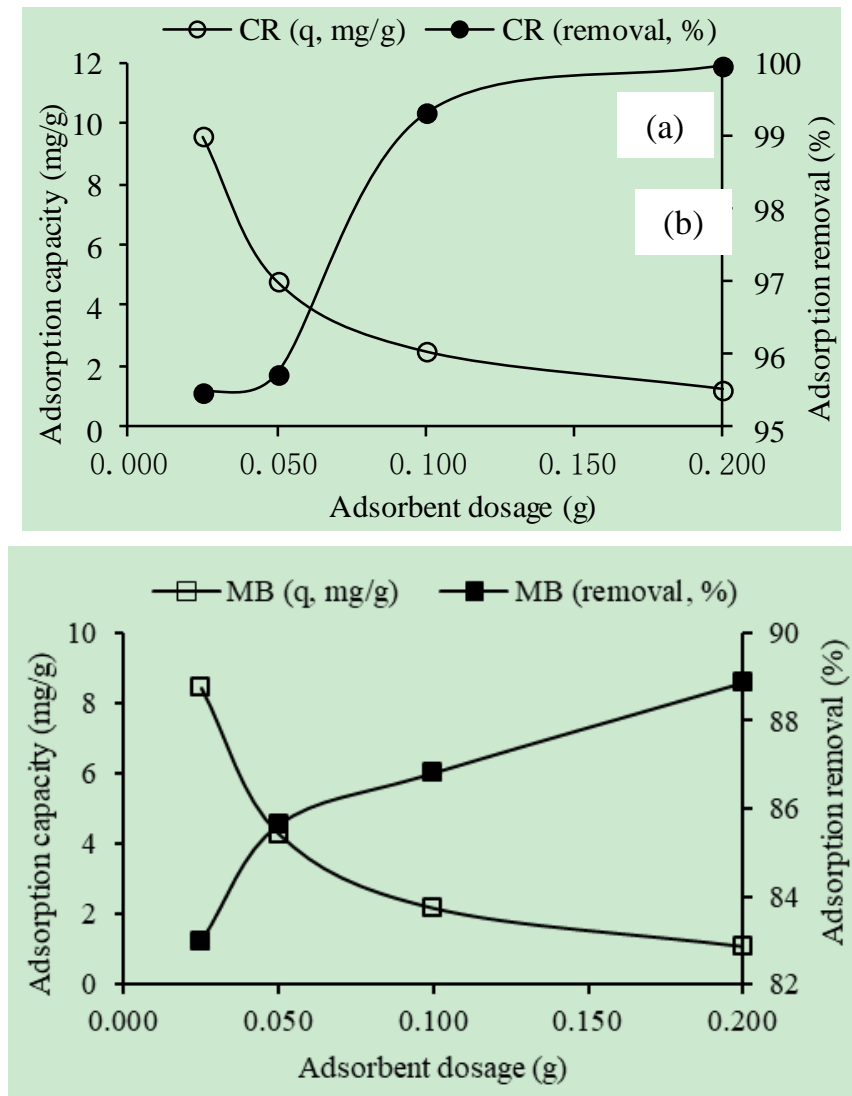

Fig. 5. Effect of dose of adsorbent on the adsorption capacity and adsorption removal of CR (a) and $\mathrm{MB}$ (b) onto RCS; $C_{\mathrm{i}}=5 \mathrm{mg} / \mathrm{L}$, optimum $\mathrm{pH}, T=$ $25^{\circ} \mathrm{C}$.

In comparison, the adsorption removal was positively related to adsorbent dosage, as can be seen in Fig. 5. The adsorption removal of $\mathrm{CR}$ and $\mathrm{MB}$ increased from 95.5 to $100 \%$ and from 83.0 to $88.9 \%$ as the dose of RSC was increased from 0.025 to $0.200 \mathrm{~g}$. This could be due to the presence of a large amount of adsorbent which provides a high surface area and more binding sites for dye adsorption [32]. Similar trends were observed previously when using other types of adsorbents [12], [33].

\section{3) Effect of initial dye concentration}

The effect of the initial dye concentration is dependent on the immediate relationship between the available active sites on the adsorbent surface and the concentration of the dyes [34]. As demonstrated in Fig. 6, the adsorption capacity has a positive correlation with initial concentration for both dyes studied. For the initial dyes concentration of $2.5 \mathrm{mg} / \mathrm{L}$, the adsorption capacities for $\mathrm{CR}$ and $\mathrm{MB}$ were 0.25 and 0.23 $\mathrm{mg} / \mathrm{g}$, respectively. When the initial concentration of CR and MB was increased to $100 \mathrm{mg} / \mathrm{L}$, their adsorption capacities increase drastically to 9.89 and $8.35 \mathrm{mg} / \mathrm{g}$. The improvement in adsorption capacity at high dye concentrations is probably 
the result of high probability of collision between dye molecules and adsorbent surface. Hence, the rate of diffusion of dye molecules into the adsorbents is expected to increase [35].
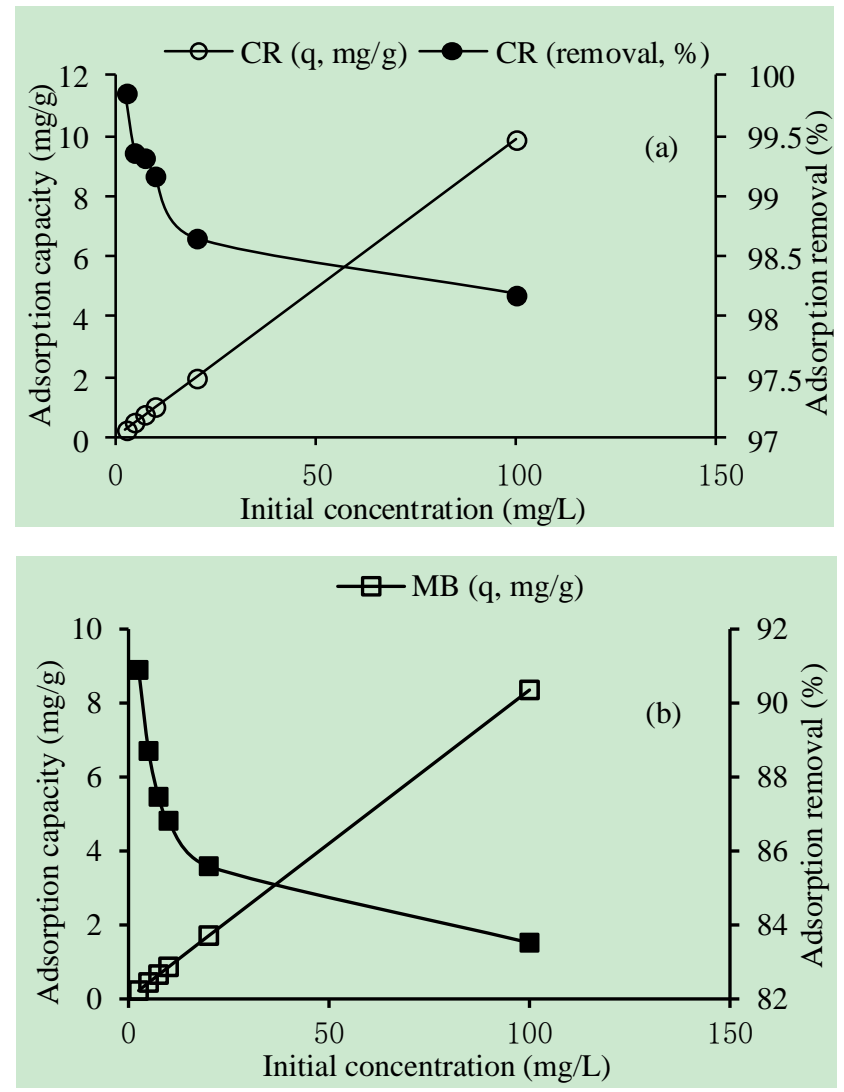

Fig. 6. Effect of initial dye concentration on adsorption capacity and adsorption removal of $\mathrm{CR}$ (a) and $\mathrm{MB}$ (b) onto RCS; $W=0.5 \mathrm{~g}$, optimum $\mathrm{pH}$, $T=25^{\circ} \mathrm{C}$.

In the contrary, the adsorption removal of $\mathrm{CR}$ and $\mathrm{MB}$ were diminished from $99.9 \%$ and $90.9 \%$ to $98.2 \%$ and $83.5 \%$ with altering the initial concentration of dyes to $100 \mathrm{mg} / \mathrm{L}$. This is due to the limited adsorption site on the RCS which becomes saturated at a certain dye concentration. At high concentrations, there will be excess dye molecules left un-adsorbed in the solution since all available binding sites have been occupied, resulting in lower removal of dyes [29]. The pattern of the corresponding dye removal in terms of adsorption capacity and removal are similar to the findings made by Li et al. [36].

\section{Adsorption Isotherms}

Adsorption isotherm is regarded as a good tool for understanding the nature of adsorbent-adsorbate interaction [37]. In order to describe the uptake of CR and MB dyes by RCS powder, the equilibrium data have been subjected to two common isotherm models, namely Freundlich and Langmuir isotherm models. In this study, adsorption equilibrium data were computed under following conditions: various initial dye concentration of 2.5-100 mg/L, optimum $\mathrm{pH}$ and $0.5 \mathrm{~g}$ of RCS.

Freundlich isotherm is an empirical equation and was developed to describe the multilayer adsorption on a heterogeneous surface [6]. Based on Freundlich isotherm, during adsorption process the most active sites will occupy first. As these binding sites are occupied by dyes, the binding strength became very weak [34]. The linearised form of the Freundlich isotherm can be expressed as equation (4) [38]:

$$
\log q_{e}=\log K_{\mathrm{F}}+\frac{1}{n} \log C_{\mathrm{e}}
$$

where $q_{\mathrm{e}}$ is the amount of dye adsorbed per unit weight of adsorbent $(\mathrm{mg} / \mathrm{g}), K_{\mathrm{F}}$ is adsorption capacity of the adsorbent $(\mathrm{mg} / \mathrm{g})$, and $n$ is the Freundlich constant. The values of Freundlich parameters, $K_{\mathrm{F}}$ and $n$ are calculated by plotting the graph of $\log C_{\mathrm{e}}$ against $\log q_{\mathrm{e}}$.

Langmuir isotherm is the simplest model assuming that the adsorption process takes place on monolayer homogeneous surface. It served to evaluate the maximum adsorption capacity of the adsorbent where cannot be reached in experiments [6]. The linearised form of Langmuir isotherm can be written as equation (5) [39]:

$$
\frac{C_{\mathrm{e}}}{q_{\mathrm{e}}}=\frac{C_{\mathrm{e}}}{Q_{\max }}+\frac{1}{Q_{\max } b}
$$

where $Q_{\max }$ is the maximum monolayer adsorption capacity $(\mathrm{mg} / \mathrm{g})$ and $b$ is Langmuir constant $(L / m g)$. The values of $Q_{\max }$ and $b$ are determined by plotting $C_{e} / q_{e}$ versus $C_{e}$.

Table I summarises the Freundlich and Langmuir isotherm parameters. Based on high correlation coefficient values $\left(R^{2}>0.95\right)$ calculated for $C R$ and $M B$, the Freundlich isotherm model is appropriate for describing the adsorption equilibrium of both dyes on RCS. The multilayer adsorption was also reported by Gupta, Kushwaha and Chattopadhyaya [37]. The CR dye has a greater probability of being adsorbed onto RCS with an adsorption capacity of $6.52 \mathrm{mg} / \mathrm{g}$ by virtue of the greater degree of charges on its surface. It carries two azo, two sulphonic and two amine groups, which could contribute to increasing the number of its charges and the electrical attraction of the dye to the adsorbent sites [5].

Another parameter called separation factor $\left(R_{\mathrm{L}}\right)$ was also calculated for further characterise of the adsorption behaviour. $R_{L}$ can be defined as equation (6):

$$
R_{\mathrm{L}}=\frac{1}{1+b C_{i}}
$$

According to Hall (1966) [40], the value of $R_{L}$ indicating that the nature of adsorption of the isotherm can be categorised into four systems: unfavourable $\left(R_{L}>1\right)$, favourable $\left(0<R_{L}<1\right)$, linear $\left(\mathrm{R}_{\mathrm{L}}=1\right)$, and irreversible $\left(\mathrm{R}_{\mathrm{L}}=\right.$ $0)$. The $R_{L}$ values obtained from Langmuir Isotherm were in the range of $0.12-0.93$, denoting that the adsorption of dyes was a favourable and applicable process.

\begin{tabular}{|c|c|c|c|c|}
\hline \multicolumn{5}{|c|}{ Freundlich } \\
\hline Dyes & $K_{\mathrm{F}}(\mathrm{mg} / \mathrm{g})$ & $n$ & $1 / n$ & $\mathrm{R}^{2}$ \\
\hline $\mathrm{CR}$ & 6.52 & 1.12 & 0.89 & 0.9533 \\
\hline MB & 0.66 & 1.18 & 0.85 & 0.9966 \\
\hline \multicolumn{5}{|c|}{ Langmuir } \\
\hline & $Q_{\max }(\mathrm{mg} / \mathrm{g})$ & \multicolumn{2}{|l|}{$b(\mathrm{~L} / \mathrm{mg})$} & $\mathrm{R}^{2}$ \\
\hline $\mathrm{CR}$ & 114.94 & \multicolumn{2}{|l|}{0.069} & 0.0075 \\
\hline MB & 23.58 & \multicolumn{2}{|l|}{0.029} & 0.5996 \\
\hline
\end{tabular}

TABLE I: FREUNDLICH AND LANGMUIR ISOTHERM MODELS PARAMETERS FOR ADSORPTION OF CR AND MB BY RCS 
The behaviour of dyes adsorption by RCS was further assessed with the value of Langmuir parameter constant (b). As discussed by Hawari and Mulligan [41], the potential of a good adsorbent was characterised by high values of $b$ [41]. Furthermore, the $n$ values ranged between 1.0 and 10 , suggesting that the beneficial adsorption of dyes onto RCS under the studied conditions.

Although a comparison of adsorption values $(\mathrm{mg} / \mathrm{g})$ recorded under different ranges of studied conditions might not be pertinent, it is necessary to compare the adsorption capacity $\left(K_{\mathrm{F}}\right)$ of RCS with other values reported previously. The RCS capacity $\left(K_{\mathrm{F}}\right)$ for $\mathrm{CR}$ and MB was compared with agricultural and industrial wastes as seen in Table II. Based on Table II, it can be concluded that the RCS showed satisfactory performance for the removal of $\mathrm{CR}$ and $\mathrm{MB}$ from aqueous solutions. Moreover, the comparisons exhibited that the adsorption capacity for CR and MB dyes by razor clam (Ensis directus) shells is comparable with other adsorbents.

TABLE II: COMPARISON OF ADSORPTION CAPACITY $\left(K_{\mathrm{F}}\right)$ OF RCS WITH WASTE-BASED MATERIALS FOR CR AND MB REMOVAL

\begin{tabular}{|c|c|c|c|}
\hline \multirow[t]{2}{*}{ Adsorbent } & \multicolumn{2}{|c|}{$\begin{array}{c}\text { Adsorption } \\
\text { capacity } \\
\left(K_{\mathrm{F}}, \mathrm{mg} / \mathrm{g}\right) \\
\end{array}$} & \multirow[t]{2}{*}{ Ref. } \\
\hline & CR & MB & \\
\hline Razor clam (Ensis directus) shell & 6.52 & 0.66 & $\begin{array}{l}\text { This } \\
\text { study }\end{array}$ \\
\hline Bengal gram seed husk & 0.57 & - & {$[11]$} \\
\hline Eichhornia crassipe roots & 1.43 & - & [31] \\
\hline Peanut shell & 0.11 & - & [42] \\
\hline Potato (Solanum tuberosum) peel & - & 2.27 & [37] \\
\hline Papaya seed & 1.43 & - & [43] \\
\hline Clay & - & 0.51 & [44] \\
\hline Cashew nut shell & 1.36 & 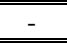 & [45] \\
\hline Fly ash & 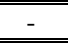 & 0.06 & [46] \\
\hline Orange peel & 0.65 & 1.75 & [47] \\
\hline Banana peel & 0.05 & 1.34 & [47] \\
\hline
\end{tabular}

\section{Desorption Study}

Desorption was done to understand the binding mechanism between the adsorbent and the adsorbate during adsorption process [11]. In this study, desorption of dye from the surface of $\mathrm{RCS}$ was done using $\mathrm{HCl}$ and $\mathrm{CH}_{3} \mathrm{COOH}$. The percentages of dyes desorbed by each eluent are listed in Table III.

From Table III, higher concentrations of $\mathrm{HCl}$ and $\mathrm{CH}_{3} \mathrm{COOH}$ favour $\mathrm{CR}$ and $\mathrm{MB}$ desorption. The figures in Table III, shows that $\mathrm{HCl}$ is a more efficient desorption agent than $\mathrm{CH}_{3} \mathrm{COOH}$ for both dyes. $\mathrm{HCl}$ is a strong acid and has been used to desorb dyes from adsorbent through ion exchange mechanism. The desorption efficiencies of CR and MB increased from $63 \%$ to $81 \%$ and $41 \%$ to $67 \%$ when the concentration of $\mathrm{HCl}$ was increased from 0.05 to $0.5 \mathrm{~mol} / \mathrm{L}$. $\mathrm{CH}_{3} \mathrm{COOH}$ at a concentration of $0.5 \mathrm{~mol} / \mathrm{L}$ produced the highest desorption of $77 \% \mathrm{CR}$ and $54 \% \mathrm{MB}$ (Table III). Acemioğlu [48] reported a similar trend of results for the removal of $\mathrm{CR}$ when using calcium-rich fly ash. It is important to note that a complete desorption of both dyes cannot be achieved even with high concentration of agents $(0.5>\mathrm{mol} / \mathrm{L})$. This could be due to the difficulty in releasing the dye trapped in the intraporous which in turn makes it difficult to release of dye from the surface of the adsorbent difficult [25]. In other word, desorption efficiencies of CR and $\mathrm{MB}$ dyes underscores the possibility of reusing the adsorbent.

TABLE III: DESORPTION OF CR AND MB BY VARIOUS CONCENTRATION OF

\begin{tabular}{|c|c|c|c|c|}
\hline \multicolumn{5}{|c|}{$\mathrm{HCL}$ AND $\mathrm{CH}_{3} \mathrm{COOH}$} \\
\hline Dye & Desorbent & $\begin{array}{c}\text { Desorbent } \\
\text { conc. }(\mathrm{mol} / \mathrm{L})\end{array}$ & $\begin{array}{c}\text { Adsorp. } \\
(\%)\end{array}$ & $\begin{array}{c}\text { Desorp. } \\
(\%)\end{array}$ \\
\hline \multirow{6}{*}{ CR } & \multirow{3}{*}{$\mathrm{HCl}$} & 0.05 & 100 & 63 \\
\hline & & 0.1 & 100 & 69 \\
\hline & & 0.5 & 100 & 69 \\
\hline & \multirow{3}{*}{$\mathrm{CH}_{3} \mathrm{COOH}$} & 0.05 & 100 & 19 \\
\hline & & 0.1 & 100 & 54 \\
\hline & & 0.5 & 100 & 77 \\
\hline \multirow{6}{*}{ MB } & \multirow{3}{*}{$\mathrm{HCl}$} & 0.05 & 88 & 41 \\
\hline & & 0.1 & 88 & 62 \\
\hline & & 0.5 & 88 & 67 \\
\hline & \multirow{3}{*}{$\mathrm{CH}_{3} \mathrm{COOH}$} & 0.05 & 88 & 33 \\
\hline & & 0.1 & 88 & 42 \\
\hline & & 0.5 & 88 & 54 \\
\hline
\end{tabular}

\section{E. Competitive and Comparative Adsorption Studies}

The effect of competition in a mixed adsorption system is considered as one of the crucial factors in the commercial application of water and wastewater treatment. This is because, in a natural setting, the presence of a mixture of toxic pollutants is more frequent than the presence of only one kind of pollutant [49]. Thus, a study on competitive adsorption aims to observe the effect of one type of pollutant on another during the treatment of real industrial wastewater [50]. Previously, environmental researchers focused on adsorption in single systems and very seldom investigate mixed adsorption systems. The present study investigates the performance of RCS and CAC for removing CR and MB from mixed dye aqueous solutions, as can be seen in Table IV.

From Table IV shows that the CR is the most affected dye in the mixed dyes system where its removal in single system was greater than in mixed system. This is probably because the presence of another dye prevent CR from binding to the adsorption sites of the adsorbent. Generally, with uncontrolled $\mathrm{pH}$, the negative charges of adsorbent's active sites $\left(\mathrm{CO}_{3}{ }^{2-}\right)$ favour the adsorption of cationic dye over anionic dye by virtue of the electrostatic attraction between two different charges. Moreover, the higher molecule weight of CR dye $(696.68 \mathrm{~g} / \mathrm{mol})$ and the longer-chain molecular structure are two of the crucial factors that prevents the adsorption of CR by RCS [51]. In contrast, MB is a cationic dye with smaller molecular weight and size, and hence is easily adsorbed in larger amounts.

The comparison shows that both RCS and CAC were able to adsorb CR and MB from mixed dye solutions (Table IV). RCS exhibited a better adsorption removal than CAC at the initial dye concentration of 20 and $100 \mathrm{mg} / \mathrm{L}$ in a mixed dye solution. Although CAC had a higher surface area as compared to RCS, the amount of dyes adsorbed by RCS was slightly greater than those adsorbed by CAC. This could be due to the operating conditions not being the most conducive for the functioning of CAC [51]. The data suggested that RCS could be a promising alternative for commercial activated carbon for the removal of anionic and cationic dyes 
in real industrial wastewater.

TABLE IV: REMOVAL OF CR AND MB DYES ONTO RCS AND CAC IN MIXED DYE SYSTEM

\begin{tabular}{|c|c|c|c|}
\hline Dye & $\begin{array}{c}C_{\mathrm{i}} \\
(\mathrm{mg} / \mathrm{L})\end{array}$ & \multicolumn{2}{|c|}{ Adsorption removal (\%) } \\
\hline \multicolumn{4}{|c|}{ RCS } \\
\hline & & Single system & Mixed system \\
\hline \multirow[t]{2}{*}{$\mathrm{CR}$} & 20 & 98.65 & 12.82 \\
\hline & 100 & 98.19 & 54.40 \\
\hline \multirow[t]{2}{*}{$\mathrm{MB}$} & 20 & 85.58 & 98.97 \\
\hline & 100 & 83.52 & 99.20 \\
\hline \multicolumn{4}{|c|}{ Mixed system } \\
\hline & & RCS & CAC \\
\hline \multirow[t]{2}{*}{$\mathrm{CR}$} & 20 & 12.82 & 4.36 \\
\hline & 100 & 54.40 & 53.49 \\
\hline \multirow[t]{2}{*}{$\mathrm{MB}$} & 20 & 98.97 & 98.50 \\
\hline & 100 & $\begin{array}{l}99.20 \\
\end{array}$ & 99.10 \\
\hline
\end{tabular}

\section{CONCLUSION}

The efficacy of RCS as an adsorbent for the removal of toxic dyes from aqueous solutions was strongly influenced by several experimental parameters such as $\mathrm{pH}$ of the solution, adsorbent dosage and initial dye concentration. According to isotherm results, the Freundlich isotherm model is suitable for describing the adsorption equilibrium of both dyes on RCS. CR dye has greater affinity towards RCS than $\mathrm{MB}$ dye and the Langmuir maximum adsorption capacity $\left(Q_{\max }\right)$ of 114.94 and $23.58 \mathrm{mg} / \mathrm{g}$ for $\mathrm{CR}$ and $\mathrm{MB}$, respectively. Furthermore, the characterisation results proved the excellent performance of RCS for adsorption of CR and MB dyes from aqueous solutions. From FTIR analysis, the key property of RCS is the presence of carbonate $\left(\mathrm{CO}_{3}{ }^{2-}\right)$ group, which is mainly responsible for the successful remediation of dyes from aqueous solutions. The desorption percentage of $\mathrm{CR}$ and $\mathrm{MB}$ exhibited the possibility of regenerating the adsorbent. In light of these investigations, it can be concluded that RCS has an excellent potential to be as an alternative adsorbent to replace costly commercial activated carbon for the removal of dyes from water environment. The application of RCS as an alternative adsorbent to sequester harmful dyes from aqueous solutions could reduce the operational cost of water treatment particularly in developing countries such as Libya and Malaysia.

\section{ACKNOWLEDGEMENT}

Lila Elamari Mohamed Areibat is thankful to Libyan Government for providing a scholarship for her M.Sc. programme. The authors thank Mr. Mohd Hashimi Ma'ani, Miss Siti Najiah Mohd Yusoff, Mrs. Johana Jumiran, Mr. Mohd Zurin Mahmood and Mr. Ibrahim Saidin for their technical assistance.

\section{REFERENCES}

[1] H. D. Setiabudi, R. Jusoh, S. F. R. M., Suhaimi, and S. F, Masrur, "Adsorption of methylene blue onto oil palm (Elaeis guineensis) leaves: Process optimaisation, isotherm, kinetics and thermodynamic studies," J. Taiwan Inst. Chem. E., vol. 63, pp. 363-370, 2016.
[2] D. M. M. Yacout and M. S. Hassouna, "Identifying potential environmental impacts of waste handling strategies in textile industry," Environ. Monit. Assess., vol. 188, pp. 1-13, 2016.

[3] L. Pereira and M. Alves, "Dyes-environmental impact and remediation," Environmental Protection Strategies for Sustainable Development, Strategies for sustainability, Springer, pp. 111-162, 2012.

[4] V. N. Devi, P. Saraswathi, and M. Makeswari, "Removal of dyes and heavy metals from aqueous solution using ricinus communis as an adsorbent - A review," Eur. J. Pharm. Med. Res., vol. 3, pp. 395-398, 2016.

[5] M. F. Attallah, I. M. Ahmed, and M. M. Hamed, "Treatment of industrial wastewater containing congo red and naphthol green using low-cost adsorbent," Environ. Sci. Pollut. Res., vol. 20, pp.1106-1116, 2013.

[6] M. V. Subbaiah and D.-S. Kim, "Adsorption of methyl orange from aqueous solution by aminated pumpkin seed powder: Kinetics, isotherms, and thermodynamic studies," Ecotoxicol. Environ. Saf., vol. 128, pp.109-117, 2016.

[7] Z.-P. Qi, Q. Liu, Z.-R. Zhu, Q. Kong, Q.-F. Chen, C.-S. Zhao, Y.-Z. Liu, M.-S. Miao, and C. Wang, "Rhodamine B removal from aqueous solutions using loofah sponge and activated carbon prepared from loofah sponge," Desalin. Water Treat., vol. 57, pp. 29421-29433, 2016.

[8] D. L. Postai, C. A. Demarchi, F. Zanatta, D. C. C. Melo, and C. A. Rodrigues, "Adsorption of rhodamine B and methylene blue dyes using waste of seeds of Aleurites moluccana a low-cost adsorbent," Alex. Eng. J., vol. 55 pp. 1713-1723, 2016.

[9] D. S. Malik, C. K. Jain, and A. K. Yadav, "Removal of heavy metals from emerging cellulosic low-cost adsorbents: A review," Appl. Water Sci., vol. 7, pp. 2113-2136, 2017.

[10] G. Z. Kyzas, J. Fu, and K. A. Matis, "The change from past to future for adsorption materials in treatment of dyeing wastewater," Materials, vol. 6, pp. 5131-5158, 2013.

[11] M. C. S. Reddy, V. Nirmala, and C. Ashwini, "Bengal gram seed husk as an adsorbent for the removal of dye from aqueous solutions-Batch studies," Arabian J. Chem., vol. 10, pp. S2554-S2566, 2017.

[12] M. T. Uddin, M. A. Rahman, M. Rukanuzzaman, and M. A. Islam, “A potential low-cost adsorbent for the removal of cationic dyes from aqueous solutions," Appl. Water Sci., vol. 7, pp. 2831-2842, 2017.

[13] J. Ťtefelová, T. Zelenka, and V. Slovák, "Biosorption (removing) of $\mathrm{Cd}(\mathrm{II}), \mathrm{Cu}(\mathrm{II})$ and methylene blue using biochar produced by different pyrolysis conditions of beech and spruce sawdust," Wood Sci. Technol., vol. 5, pp. 1321-1338, 2017.

[14] M. A. Ahmad, N. Ahmad, and O. S. Bello, "Modified durian seed as adsorbent for the removal of methyl red dye from aqueous solutions," Appl. Water Sci., vol. 5, pp. 407-423, 2015.

[15] J. Yu, W. Xiong, J. Zhu, J. Chen, and R. Chi, "Removal of congo red from aqueous solution by adsorption onto different amine compounds modified sugarcane bagasse," Clean Tech. Environ. Policy., vol. 19, pp. 517- 525., 2016.

[16] A. Tripathi and M. R. Ranjan, "Heavy metal removal from wastewater using low-cost adsorbents," J. Biorem. Biodegrad., vol. 6, pp. 1-5, 2015 .

[17] K. H. Mo, U. J. Alengaram, M. Z. Jumaat, S. C. Lee, W. I. Goh, and C. W. Yuen, "Recycling of seashell waste in concrete: A review," Constr. Build. Mater., vol. 162, pp. 751-764, 2018.

[18] S. Brunauer, P. H. Emmett, and E. Teller, "Adsorption of gases in multi-molecular layers,” J. Am. Chem. Soc., vol. 60, pp. 309-319, 1938.

[19] E. P. Barrett, L. G. Joyner, and P. P. Halenda, "The determination of pore volume and area distributions in porous substances. I. Computations from nitrogen isotherms," J. Am. Chem. Soc., vol. 73, pp. 373,1951

[20] M. N. M. Ibrahim, W. S. W. Ngah, M. S. Norliyana, W. R. W. Daud, M. Rafatullah, O. Sulaiman, and R. Hashim, "A novel agricultural waste adsorbent for the removal of lead (II) ions from aqueous solutions," $J$. Hazard. Mater., vol. 182, pp. 377-385, 2010.

[21] S. Dawood and T. K. Sen, "Removal of anionic dye congo red from aqueous solution by raw pine and acid-treated pine cone powder as adsorbent: Equilibrium, thermodynamic, kinetic, mechanism and process design," Water Res., vol. 46, pp. 1933-1946, 2012.

[22] S. K. Bazbaş and Y. Boz, "Low-cost biosorbent: Anadara inaequivalvis shells for removal of $\mathrm{Pb}$ (II) and $\mathrm{Cu}$ (II) from aqueous solution," Process Saf. Environ. Prot., vol. 103, pp. 144-152, 2016.

[23] A. Kamari, W. P. Putra, N. S. Abd Wahid, and S. N. M. Yusoff, "Cerithidea obtuse (Mud Creeper snail) shell as a green biosorbent for adsorption for $\mathrm{Cu}(\mathrm{II}), \mathrm{Ni}(\mathrm{II})$ and $\mathrm{Pb}$ (II) ions from aqueous solutions," Fresen. Environ. Bull., vol. 24, pp. 575- 586, 2015. 
[24] A. A. Inyinbor, F. A. Adekola, and G.A. Olatunji, "Adsorption of rhodamine B from aqueous solution on Iringia gabonensis biomass: Kinetics and thermodynamic studies," S. Afr. J. chem., vol. 68, pp. 115-125, 2015.

[25] C. Umpuch and S. Sakaew, "Removal of methyl orange from aqueous solution by adsorption using chitosan intercalated montmorillonite," Songklanakarin J. Sci. Technol., vol. 35, pp. 451- 459, 2013.

[26] R. Ansari, B. Seyghali, A. Mohamed-khah, and M. A. Zanjanchi, "Highly efficient adsorption of anionic dyes from aqueous solutions using sawdust modified by cationic surfactant of cetyltrimethylammonium bromide," J. Surfactants deterg., vol. 15, pp. 557-565, 2012.

[27] F. Kallel, F. Chaari, F. Bouaziz, F. Bettaieb, R. Ghorbel, and S. E. Chaabouni, "Sorption and desorption characteristics for the removal of a toxic dyes, methylene blue from aqueous solution by a low cost agricultural by-product," J. Mol. Liq., vol. 219, pp. 279-288, 2016.

[28] N, Sivarajasekar, R. Baskar, T. Ragu, K. Sarika, N. Preethi, and T. Radhika, "Biosorption studies on waste cotton seed for cationic dyes sequestration: Equilibrium and thermodynamics," Appl. Water Sci., vol. 7, pp. 1987-1995, 2017.

[29] A. A. Kamaru, N. S. Sani, and N. A. N. N. Malek, "Raw and surfactant-modified pineapple leaf as adsorbent for removal of methylene blue and methyl orange from aqueous solution," Desalin. Water Treat., vol. 57, pp. 1-15., 2016.

[30] S. Dashamiri, M. Ghaedi, A. Asfaram, F. Zare, and S. Wang, "Multi-response optimization of ultrasound assisted competitive adsorption of dyes onto $\mathrm{Cu}(\mathrm{OH})_{2}$-nanoparticle loaded activated carbon Central composite design," Ultrason. Sonochem., vol. 34, pp. 343-353, 2017.

[31] W. C. Wanyonyi, J. M. Onyari, and P. M. Shiundu, "Adsorption of congo red dye from aqueous solutions using roots of Eichhornia crassipes: Kinetic and equilibrium studies," Energy Procedia., vol. 50, pp. 862-869, 2014

[32] R. Lafi, A. Fradj, A. Hafiane, and B. H. Hameed, "Coffee waste as potential adsorbent for the removal of basic dyes from aqueous solution," Korean J. Chem. Eng., vol. 31, pp. 2198-2206, 2014.

[33] Y. O. Khaniabadi, R. Heydari, H. Nourmoradi, H. Basiri, and H. Basiri, "Low-cost sorbent for the removal of aniline and methyl orange from liquid-phase: Aloe Vera leaves wastes," J. Taiwan Inst. Chem. E., vol. 68, pp. 90-98, 2016.

[34] U. J. Etim, S. A. Umoren, and U. M. Eduok, "Coconut coir dust as a low cost adsorbent for the removal of cationic dye from aqueous solution,” J. Saudi Chem. Soc., vol. 20, pp. S67-S76, 2016.

[35] M. El-Sadaawy and O. Abdelwahab, "Adsorptive removal of nickel from aqueous solutions by activated carbons from doum seed (Hyphaenthebaica) coat," Alex. Eng. J., vol. 53, pp. 399-408, 2014.

[36] H. Li, N. An, G. Liu, J. Li, N. Liu, M. Jia, W. Zhang, and X. Yuan, "Adsorption behaviors of methyl orange dye on nitrogen-doped mesoporous carbon materials," J. Colloid Interface Sci., vol. 466, pp. 343-351, 2016

[37] N. Gupta, A. K. Kushwaha, and M. C. Chattopadhyaya, "Application of potato (Solanum tuberosum) plant wastes for the removal of methylene blue and malachite green dye from aqueous solution," Arabian J. Chem., vol. 9, pp. S707-S716, 2016.

[38] H. M. F. Freundlich, "Uber die adsorption in lasungen," J. Phys. Chem., vol. 57, pp. 385-470, 1906.

[39] I. Langmuir, "The adsorption of gases on plane surfaces of glass, mica and platinum," J. Am. Chem. Soc., vol. 40, pp.1361-1403, 1918.

[40] K. R. Hall, L.C. Eagleton, A. Acrivos, and T. Vermeulen, "Pore-and solid-diffusion kinetics in fixed-bed adsorption under constant-pattern conditions," Ind. Eng. Chem. Fundam., vol. 5, pp. 212-223, 1966.

[41] A. H. Hawari and C. N. Mulligan, "Biosorption of lead(II), cadmium(II), copper(II) and nickel(II) by anaerobic granular biomass," Bioresour. Technol., vol. 97, pp. 692-700, 2006.

[42] A. Abbas, S. Murtaza, K. Shahid, M. Munir, R. Ayub, and S. Akber, "Comparative study of adsorptive removal of congo red and brilliant green dyes from water using peanut shell," Middle-East J. Sci., vol. 11, pp. 828-832, 2012.
[43] N. Nasuha, H. Z. Zurainan, H. I. Maarof, N. A. Zubir, and N. Amri, "Effect of cationic and anionic dye adsorption from aqueous solution by using chemically modified papaya seed," ICOESE., vol. 8, pp. 50-54, 2011.

[44] A. A. N. Moghaddam, G. D. Najafpour, A. A. Ghoreyshi, and M. Mohammadi, "Adsorption of methylene blue in aqueous solution phase by fly ash, clay and walnut shell as adsorbents," World App. Sci. J., vol. 8, pp. 229-234, 2010.

[45] P. S. Senthil Kumar, S. Ramalingam, C. Senthamarai, M. Niranjanaa, P. Vijayalakshmi, and S. Sivanesan, "Adsorption of dye from aqueous solution by cashew nut shell: Studies on equilibrium isotherm, kinetics and thermodynamic of interactions," Desalination, vol. 261, pp. 52-60, 2010.

[46] T. A. Khan, I. Ali, V. V. Singh, and S. Sharma, "Utilisation of fly ash as low-cost adsorbent for the removal of methylene blue, malachite green and rhodamine B dyes from textile waste water," J. Envir. Protect. Sci., vol. 3, pp.11-22. 2009

[47] G. Annadurai, R.-S. Juang and D.-J. Lee, "Use of cellulose-based wastes for adsorption of dyes from aqueous solutions," J. Hazard Mater., vol. B92, pp. 263-274, 2002.

[48] B. Acemioğlu, "Adsorption of congo red from aqueous solution onto calcium-rich fly ash," J. Colloid Interface Sci. vol. 274, pp. 371-379, 2004.

[49] J. Kwon, S. Yun, J. Lee, S. Kim, and H. Y. Jo, "Removal of divalent heavy metals $(\mathrm{Cd}, \mathrm{Cu}, \mathrm{Pb}$, and $\mathrm{Zn})$ and arsenic (III) from aqueous solution using scoria and equilibria of sorption," Hazard. Mater., vol 174, pp. 307-313, 2010.

[50] P. Chand and Y. B. Pakade, "Synthesis and Characterisation of hydroxyapatite nanoparticles impregnated on apple pomace to enhanced adsorption of $\mathrm{Pb}$ (II), $\mathrm{Cd}(\mathrm{II})$, and $\mathrm{Ni}$ (II) ions from aqueous solution," Environ. Sci. Pollut. Res., vol. 22, pp. 10919-10929, 2015.

[51] D. C. W. Tsang, J. Hu, M. Y. Liu, W. Zhang, K. C. K. Lai and I. M. C. Lo, "Activated carbon produced from waste wood pallets: Adsorption of three classes of dyes," Water, Air, Soil Poll., vol. 184, pp. 141-155, 2007.

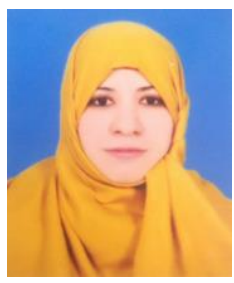

Lila Elamari Mohamed Areibat is currently a postgraduate student in master of science (analytical chemistry) programme at Universiti Pendidikan Sultan Idris. His research interest focuses on development of low-cost adsorbents for water treatment

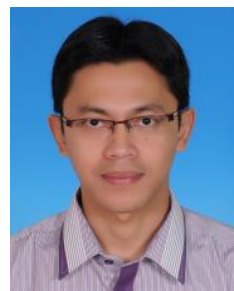

Azlan Kamari obtained his B.App.Sc. (hons) and M.Sc. in analytical chemistry from University of Science, Malaysia. He completed his Ph.D in environmental analytical chemistry at University of Glasgow, Scotland, United Kingdom. He is currently an associate professor at Department of Chemistry, Faculty of Science and Mathematics, Sultan Idris Education University, Malaysia. His research interes focuses on the use of waste-based materials for the remediation of contaminated water and soil.

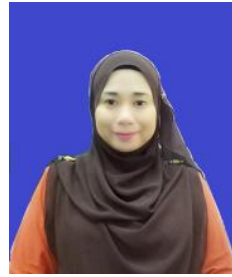

Shahrulnizahana Mohammad Din received her B.App.Sc. (hons) from University of Science, Malaysia. She completed her M.Sc. in analytical chemistry and instrumentation at University of Malaya, Malaysia. She is currently a senior chemist at Department of Chemistry Malaysia, Johore State. Her research interest focuses on application of spectroscopic and chromatographic techniques for environmental analyses. 